\begin{tabular}{l|l|l|l|l}
\hline Volume 2 & Issue 1 & April (2021) & DOI: 10.47540/ijsei.v2i1.180 & Page: $68-77$ \\
\hline
\end{tabular}

\title{
Climate Change and Impacts of Extreme Events on Human Health: An
}

\section{Overview}

\author{
Aadil Gulzar ${ }^{1}$, Tajamul Islam², Ruquia Gulzar ${ }^{3}$, Tabasum Hassan $^{4}$ \\ ${ }^{1}$ Department of Environmental Science, University of Kashmir, Srinagar, India \\ ${ }^{2,3,4}$ Department of Botany, University of Kashmir, Srinagar, India
}

Corresponding Author: Aadil Gulzar; Email: ehaan900@gmail.com

\begin{tabular}{ll}
\hline A R T I C L I N F O & A B S T R A C T \\
Keywords: Anthropogenic; Climate & The causes of climate patchy rope in heat up the temperature, change in \\
Change; Diseases; Human Health; & precipitation, degree of utmost conditions occasions like melting of glaciers, polar \\
Population. & ice-caps, mount in sea levels, etc. These impacts eventually fall our income by \\
& touching the rations we eat, the water we drink, the air we breathe, and the earth \\
Received : 08 March 2021 & somewhere we live. Frequent impacts are caused fitting to excessive exposure to \\
Revised $: 17$ April 2021 & heat waves such as round stroke, dehydration, cardiovascular, respiratory, and \\
Accepted $: 20$ April 2021 & neural comorbidities. Climate conversion alters the ecology of vectors and these \\
& vectors are capable of having in stock causal agents such as viruses, bacteria, and \\
& protozoa from animals to humans. Malaria, tick-borne encephalitis, fair fever, \\
& plague, and dengue obtain lengthened their geographical ranges as their carriers \\
& migrated to privileged latitudes. Droughts canister take part in adverse property on \\
being healthy, as they over and over again suggest themselves in mishmash with \\
other sit-out conditions, such as warm waves, wildfires, and dust storms. Reduced \\
water quantity may cause decreased water flow during periods of drought, \\
encouraging the development of pathogens that prefer dry, stagnant environments. \\
Altering climatic situation know how to be attributed to mounting international \\
temperatures, spread in the dimensions of ambient fill up fumes and changes in the \\
announce motion as mutual together. Extreme season and climate-related actions \\
are famous to set off fundamental infrastructure failures, lucrative harm, and \\
relocation of communities, ensuing in a quantity of health problems.
\end{tabular}

\section{INTRODUCTION}

Fossil fuels are painstaking to be the fund bone of rising mechanized world, awaited to amplified utilization of fossil fuels, $\mathrm{Co}_{2}$ emissions grasp contributed to the total climate exchange to a larger extent. As result, insecurity has been identified as a major challenge for the world in the $21^{\text {st }}$ century (Curtis, 2007; McCartney et al., 2008; Moriarty and Honnery 2009; Fantazzini et al., 2011). The giving off of $\mathrm{CO}_{2}$ and other gases by the ignition of fossil fuels has momentously contributed towards universal climate warming. Other hothouse gases like Methane, Nitrous oxide, and ozone-depleting substances moreover suffer noteworthy payment towards the Climate transformation (Montza et al., 2011). As for each United Nations IPCC on paper numerous gossip which offers unambiguous confirmation for the part of individual behavior as an influential compel in the warming of Earth's surface by about $1{ }^{\circ} \mathrm{C}$ since 1850 .

The global average temperature has to move upward by around $1{ }^{\circ} \mathrm{C}$ since the pre-industrial phase. Natural variations are not the indicator of time of warming until the anthropogenic actions are obliged to accept into consideration. Liberation of unusual conservatory gases (GHGs) and aerosols revise the atmospheric constitution and settle shelter (LULC) changes during the industrialized part in addition combine synergetic effect. Dynamics of climate extremes such as stage waves, droughts, gray rain, and the rest hold augmented ten folds from past decades. Each of the past three decades has been constantly heater than any preceding decade since 1850 (Stocker et al., 2013) and the days between 2001-2018 enclose been 18 of the 19 heartfelt days in the observational record. At the 
expound charge of intensification in temperature, it is predicted that comprehensive warming will access the sign of $1.5{ }^{\circ} \mathrm{C}$ between 2030 and 2052 and $3-5^{\circ} \mathrm{C}$ by the side of this century comparative to pre-industrial phases even though underdeveloped countries emit a small proportion of global greenhouse gas but the extreme effects on their health are disproportionate. This creates an injustice with small income countries and it will further intensify global health disparities (McMichael et al., 2003; Patz and Olson, 2006; Patz et al., 2007; Wiley and Gostin, 2009). altering high temperature and rain patterns constantly adhere to climate alteration will spread shape person health by altering the ecology of many vector-borne diseases such as malaria, dengue, chikungunya, Japanese encephalitis, kala-azar, and all that (Bhattacharya et al., 2006; Dhiman et al., 2008). Climate change effects human health to cover the trajectory of time past, present, and future.

\section{Weather versus Climate Change}

Weather is defined at a given time as the state of the atmosphere in a given location and can be represented for a given meteorological station or for a particular surface region of the earth. Conversely, climate represents the prevalent atmospheric prerequisite consequential from extensive observational periods. Hence, the in a row of the last is immediately obtained from the comprehension of the former. We know how to tell that climate is a generality time come through represents the exact event. In other languages, the climate is an abstract name for the reason that its fundamentals which describe it and through which it affects other gears of the untreated and creature environment (Lemieux and Scott, 2010). UNFCCC definite climate amendment as "a modification of climate which is attributed soon or indirectly to person doings that alters the makeup of the macro feeling and which is in a surcharge to biological climate unevenness experimental over equivalent periods."

Climate modify is a valuable subject nowadays and we are facing a dangerous situation. Climate change's impacts are comprehensive in scenery and exceptional in scope, from shifting season patterns that threaten foodstuff creation to escalating sea levels that augment the likelihood of catastrophic flooding. Without immediate action today, adjusting to those impacts would be more complicated and expensive in the future. Climate change is usually defined in terms of average changes in temperature or other weather patterns, but much of the economic and social consequences of climate change may arise as a result of adjustments in the amount and intensity of severe incidents. Individual weather events give valuable lessons about climate change's social and economic vulnerabilities (Huber et al, 2011). This is demonstrated by a large number of expensive weather disasters in 2010 that caused 2005 to be the world's warmest year since 1880 . Unsurprisingly, both years have been remembered for particularly destructive weather disasters, including the 2005 Hurricane Katrina and the 2010 devastating heat wave of Russia. Other notable events of 2010 include the largest flood in Pakistan, the warmest year of Canada, and the driest year in Southwest Australia. Clearly, specific weather events provide important insights on social and economic climate change vulnerabilities.

As we know climate change is observed in terms of change in mean climatic conditions for a period of time. In this connection, many studies have now explored linkages between real and expected temperature fluctuations and climate change expectations (Li et al., 2011; Howe et al., 2013; Capstick and Pidgeon, 2014; Zaval et al., 2014). Although climate change is projected to contribute to overall global temperature rises, extreme weather events (EWEs) are one of the key ways in which it is expected to be rendered real for common citizens at a local level (Coumou and Rahmstorf, 2012). For example, in China extreme heat and the worst drought in 100 years struck Yunan province, resulting in crop failures and setting the stage for locust swarms to devastate further. In the United States, the summer of 2010 saw record-breaking heat on the east coast, with temperatures reaching 106 degrees north as far as Maryland. Records were also set for energy. Changing climatic conditions can be attributed to increasing global temperatures, rise in the volume of ambient water vapors, and changes in the air circulation when combined together. Warmer temperatures directly enhance heatwaves and raise atmospheric moisture to produce intense precipitation events. Widening subtropical deserts expanding from the equator produce greater areas of cooling, dry air, and widening the area of droughtprone land. The extension of this subtropical 
circulation system also increases heat transfer from the tropical areas to the Arctic and drives midlatitude storm tracks to higher latitudes along with their rainfall (Gulledge and Huber, 2011). Survey researchers recently checked whether or not objectively calculated weather affects assumptions about climate. Data from various rural areas were analyzed, in snow-country regions with winter warming trends; it was found that perceived local impacts of climate change were greatest in these areas (Hamilton and Keim 2009). (Shao 2012) found correlations between decadal trends in temperature and public concern about global warming.

Extreme weather and climate events have large impacts on both the social and biophysical systems. Extreme events may come in many forms and sizes. The multitude of forms of extreme events has also contributed to a proliferation of meanings suitable at various times and locations for different applications (Ferro, McGregor, and Stephenson, 2005). Climate change influences almost every field of human life. For example, climate forecasts usually predict a shortened mounting term and chow creation decline across the Sahel and parts of southern Africa. Storm surges, particularly in the compactly populated coastal cities in Asia, may escort to large-scale flooding, ensuing in passing a way of life, and harm to analytical infrastructure in chief haven cities such as Shanghai. One scrutiny creates that a tenth of the world's population-634 million dwell in - lives between zilch and ten meters above sea balanced in the coastal areas, 75 for each cent of individuals who live in Asia. For instance, Bangladesh has 46 for each cent of its people in quiet-height areas, with loads of public residing in areas below five meters above sea level (Busby 2008). Obviously, economic activities are affected by changes in climate and weather, and recreational activities such as tourism are the most affected ones. It means that certain parts of the world have little potential for tourism because their climate is not conducive for tourism opportunities. Tourism managers do not support or prefer these regions, because this does not produce large revenues. The traveler who still visits these regions has to deal with high costs (e.g. fuel costs) or physical pain e.g. body strain (Matzarakis, 2006). There is more to a potential connection between global warming and extreme weather than academic interest. The cultural, human, and environmental costs of just a slight rise in extremes over the long term will be substantial (Francis and Hengeveld, 1998). The history of extreme events over recent decades, taken in aggregate, offers a few indications of a broader statistical trend towards more common and severe extreme weather events. Increasing heavy precipitation frequency is a predicted consequence of a warming environment, and this trend has been observed. Certain areas will see more droughts as the average rainfall falls, and heavy rainfall occurs more frequently in other regions. Many areas do not see a change in the average amount of rainfall, but may receive rain unusually; more extreme bursts, possibly leading to flash floods punctuating prolonged drought cycles. Hence observed global warming is consistent with increases in temperature, heavy precipitation, and drought in different areas (Huber et al., 2011).

\section{Anthropogenic Impact on Climate Change}

Human beings are considered to be one of the significant contributors to climate change. Since the beginning of the earlier period (approx. 1750), the human activities have importantly contributed regarding the atmospheric warming drift (IPCC 2007). In 2013, the fifth assessment report of IPCC, it was concluded that human activities were responsible for global warming over the last 50 years and probability was almost 95 to $100 \%$ in this assessment (IPCC 2013). Anthropogenic activities contributed towards climate change through the following means: (1) Burning of fossil fuels and greenhouse gas emissions; (2) Deforestation and enhanced forest fires; (3) Increasing aerosol concentration in the atmosphere; (4) Industrialization, urbanization, and vegetation pattern shifts

\section{Deforestation and enhanced Forest fires}

Deforestation is the cutting of tree cover for other land uses. The anthropogenic activities responsible for deforestation vary among different forest types. One of the main reasons is the construction of roads through forests which is considered the first step towards gaining access to forest areas for agricultural usage (Tomich et al., 2003). The enhanced deforestation causes a change in carbon fluxes in soil, vegetation, and atmosphere (CRS Report) which is considered one of the main factors responsible for contemporary climate change. Anthropogenic forest fires on the other hand are considered to be one of the significant 
factors responsible for carbon emissions, which contributes to global warming e.g., in Tropical forests anthropogenic ignitions are the dominant factors responsible for forest fires (Cochrane et al., 2008).

\section{Increasing Aerosol Concentration in the atmosphere}

Aerosol particles influence the atmospheric temperature by dispersing and absorbing radiations and by acting as cloud condensation nuclei. Aerosols are responsible for creating a negative radiative force at the upper layer of the atmosphere and therefore overcome the warming caused by greenhouse gases. Thus aerosols are responsible for changes in atmospheric temperature.

\section{Industrialization, urbanization, and vegetation pattern shifts}

The industrial revolution which began in 1850 continuously evolves to accumulate the capital allowed investments. The large emissions of gases and other industrial effluents have greatly contributed to the changing global climate. The changes in land-use patterns and increased urbanization caused by human activities also alter the climate, resulting in changes to the Earth's albedo.

\section{Impacts of Extreme Events on Human Health}

Excessive procedures are regularly speedily restricted but fast to define. This is for a range of reasons. First, there is no specific meaning for what the term serious or extreme means: there are many meanings in common usage. Second, the outlining of 'extremity' is subjective and relies precisely passionately on meaning. Intense dealings are by and large definite as actions having major principles of convinced metrological factors. For paradigm prohibitive quickness winds, piercing temperatures, floods, dearth, and the rest. These actions are uncommon but awfully harmful (Diaz, Murnane, and Stephenson, 2008). Different aspects of tremendous measures are of concern. These contain the moment of events, the glassy of likelihood or return, the time spot of the event, the spatial scale, timing, rendezvous or seasonality, and preconditioning. In this context, preconditioning refers to the precedent state of affairs that push or let the occurrence or alteration of its characteristics of any intense event. For instance, before deficits in soil humidity that accumulate in chill/movement over quite a lot of months suffer been given away to intensify summer section wave and drought (Seneviratne et al., 2012).

Utmost climate and climate-related procedures are acknowledged to basis fundamental infrastructure failures, money-making spoil, and relocation of communities, ensuing in a numeral of health tribulations (Bell et al., 2016). The health implications connected with climate-related changes in ruthless happening exposure contain death, disability, or disease; exacerbation of presented checkup conditions; and adverse mental health effects. The disposition and duration of health personal property linked with plain measures depend on the substantial impacts of these procedures themselves and the limited individual, social, and environmental environment at the time and lay everyplace these dealings occur. This development album of factors tin ease or aggravate health outcomes and liability accompanied by the people and communities precious (Bell et al., 2016). In coastal populations with better exposure to coastal flooding, health-coupled evils are faced recurrently by the settle with disabilities or other admission and functional needs, a mixture of shade communities, leader adults, pregnant women and babies, low-income populations, and particular manufacturing groups (unaffordable confidence). The in the public domain Climate Assessment news that "human climate wallop is horizontal to resume and to substantially down on if thorough emissions of heat-trapping gasses most recent to increase" (Field, 2012; Stocker et al., 2013; Melillo et al., 2014). Probe from European countries, as well as the United Kingdom, suggests that the stimulus on midpoint infrastructure behind health martial includes flooded health amenities (sometimes follow-on in long-suffering evacuation), power and moisten interruptions, long-suffering proceedings guarantee, and access, disruption of ambulance services, continuity of outreach and shared essence care hand commands evident health asking price of UK floods take up similarly uncommon risks of drowning; injury from hard at it or floating debris, liven up or electrocution; toxicity or illness coupled with deficiency or pollution. There is a particular indication of mental and rude morbidity linked with flood exposure with potentially longer-term and staid impacts on the common attention to detail system (Menne and Murray 2013; Curtis et al., 2017). Severe weather conditions lead to a selection 
of hose-down borne diseases in the increasing world grimy hose intake represents the means procedure of personal exposure that connects great procedures to person health risk. Certain changes in known health and financially viable prosperity, the incidence of intestinal infection relics extreme and under the manipulation of climate coins this site may deteriorate much (Marcheggiani et al., 2010). Droughts be able to include adverse personal property on being healthy, as they frequently come to mind in mixture with other endure conditions, such as ardor waves, wildfires, and dust storms. These pathways to health outcomes are able to be undeviating and indirect, with dreadfully nuanced and up-and-down indirect pathways (Stanke et al., 2013). Apart from the bargain availability of water, periods of famine be capable of arrangement irrigate quality. Reduced water quantity during a period of droughts, cheering the expansion of pathogens which like better dry, still environments (Delpla et al., 2009; Whitehead et al., 2009). For example, droughts were linked to changes in the distribution of vector-borne diseases, particularly for mosquitoes, because they depend on stagnant water to reproduce. For certified areas, mosquitoes transport West Nile virus (WNV) are new expected to fall into associate with WNV-infected birds for the reason that at hand are take away dampen supplies, raising the likelihood of cohabitation and in this fashion transmission of WNV (Johnson and Sukhdeo 2013). Dislocation of communities from wildfires and dearth know how to plus head to diverse outcomes ranging from demands on mental health position to health trouble system impacts. Enhanced pouring rain actions decline the exposed class in as satisfactorily as outdoors. intense rain proceedings be capable of foundation hurt to the house, as a result, ingress of fill up and damp into interior areas, on condition that an air for make lump and the escalation of other aero allergenic substances that basis allergic rhinitis and asthma (Clark et al., 2004; IOM 2011; Johanning et al., 2014). Hurricanes are especially destructive to vulnerable populations as are other climate-related hazards. Many of the victims of the New Orleans levee collapse during Katrina were low-income, older adults, and people of color. Katrina's health impacts also lingered long after the waters receded. None of the evacuees returned to New Orleans, putting compel on healthcare systems across the country (Luber et al., 2014).

In short, health impacts of acute actions are apt to be overpoweringly pessimistic and encompass an important crash on low-income countries everywhere adaptation latent is lowest, but too on the largely vulnerable groups in industrial countries. With climate substitute by now underway, vulnerabilities necessitate being assessed and costeffective interference/adaptation options poverty to be identified in the health sector and other sectors that retain level family to personal health. Operational grounding will advantageous to relieve budding harmful health possessions and easing strategies e.g., via a diversity of sustainable sources of energy will pick up protection by minimizing circulate emissions and extenuating climate change.

\section{Infectious Diseases Due to Climate Change}

In the modern era, the intensity of some infectious diseases has increased tremendously because of changing climatic conditions. The alterations in climate variables viz temperature, precipitation, and wind due to contemporary climate change have caused a severe impact on the reproductive cycle of some diseases, causing pathogens, thereby affect their distribution boundary and means of their transmission environment. Historical records of infectious disease and their relation with climate change can be traced back to 1878 when a deadly yellow fever epidemic outbreak took place in several cities in the United States after a great El Nino event. The reason for this major outbreak was fluctuating precipitation and warm, wet El Nino conditions. Moreover, between 1870 and 1880 , there is a greater increment in the number of cities affected by a yellow fever epidemic with the global El Nino index, which may be responsible for the multiple health threats to human beings.

\section{Effect of Climate change on pathogens}

Climate change can impact the pathogen directly by influencing its survival rate and reproductive cycle or indirectly through influencing its surrounding environment or competition. An example of an outbreak where infectious disease is related to an increment in water temperature is presented here. In Alaska in July 2004, a sudden outbreak of gastroenteritis disease caused by V. parahaemolyticus was reported among cruise ship passengers. They were reported to consume oysters. 
The reason for this outbreak was summer mean temperature of the oyster farm which exceeded $15^{\circ} \mathrm{C}$ to the threshold temperature. An increase in the average temperature of water bodies is also responsible for the proliferation of algal blooms and other microorganisms e.g. rising temperatures of Baltic and the North Sea during the year 2006 was responsible for the proliferation of Vibrio Species. Increased temperature between the range $7^{\circ} \mathrm{C}$ and $37^{\circ} \mathrm{C}$ favors the reproduction rate of bacteria responsible for Salmonellas, a food-borne disease. Rising temperature not only favors the proliferation of pathogen but also limit their reproduction and proliferation by providing suitable environment to their competitors. For example, Population declines of Campylobacter spp. The bacteria are considered to be outcompeted by other bacteria. The reason for their decline was warmer temperatures which proved favorable for other competing species to flourish. Hence survival of Campylobacter was prohibited.

\section{Effect of Climate change on hosts/Vectors}

Hosts are the biological entities in or on which a disease-causing organism resides. While as vectors are biological carriers that carry pathogens between two living hosts. Change in climatic conditions is responsible for changing the spatiotemporal distribution of vectors. e.g. Some vector species are present in low latitude ranges. As the temperature rises, these vectors migrate to mid or high latitudes which became new favorable habitats for these species to flourish.. These distributional shifts became responsible for the geographical expansion of infectious diseases.

Malaria, tick-borne encephalitis, yellow fever, plague, and dengue have expanded their geographical ranges as their carriers migrated to higher latitudes. Increasing temperature not only widens the distributional range of vector species but also constrains it (Epstein, 2001) e.g., Rise in temperature is responsible for the decline of A. aegypti from some regions of the world. The species is a host for yellow fever and dengue fever viruses as the temperature rises above $40{ }^{\circ} \mathrm{C}$, the adults of this species start to decline.

\section{Effect of climate change on transmission season}

Several infectious diseases exhibit particular cyclic seasonal patterns e.g., Vector-borne diseases like malaria and dengue fever show particular seasonal patterns. The spread of these diseases is highest in the Monsoon season, which is characterized by the highest rainfall and humidity. But due to changing climatic conditions most of these infectious diseases show significant seasonal fluctuations which may lead to disease an outbreak.

\section{Monitoring the Impact on Human Health versus Climate Change}

Human health has usually influenced by various factors, particularly by climate and weather. Variation in climate particularly changes in weather extremes, impacts both biotic and abiotic factors of the environment that facilitates our wellbeing. The synergetic impact of natural and anthropogenic stressors halts the state of well-being as experienced in the USA.

This is unambiguous that the earth has warmed since 1900 A.D. Numerous analyses of different parameters such as air and ocean temperatures, sea level, snow, and ice have depicted the variations to be unparalleled over decades to centuries. An anthropogenic impact has been the predominant explanation of this current warming (Akinbami et al., 2012). Implementation of both national, as well as an international framework relating control and alternative roads, needs the examination and magnitude of climate change on human health. Proof of impact on health and can gather from judicial data. Not only anthropogenic activities but naturally alters the climate. There is a sophisticated and complex association between climate change and health. An Environment is dynamic and versatile, gets changed continuously. Henceforth, alters the climate that leads to the monitoring of the health (Haines et al., 1993; Haines, 1999). Robust and accurate data are important for scrutiny and quantifying the early stage of impacts on human health; it helps in mitigation of adverse effects in future era and is an essential and first step towards an environmentally changed world (McMichael et al., 1996; Balbus, 1998).

A change in health status or profile is the flagship for monitoring the impact of climate. There should be following five points on which the climate change monitoring relies: (1) Detection of the effects of climate change on human health at an early stage; (2) Quantitative analysis of the interrelationships between human health and climate change; (3) Satisfied scrutiny of susceptibility due to the climate change; (4) 
Reliable prediction of impacts on human health due to climate change in the future and proper validation of predictions; (5) Analysis of an impact on adaptation strategies.

The uncertainty in climate change involves many biological and physiological parameters of health. The belongings of climate convert on health depend on something else parameters and environment like recurrent unevenness in individual health. Disease tin be classified as noncommunicable and catching and are in general indirect, and regularly catalyzed through neurosis ecological ecosystems. Unfortunately, we accumulate a reduced amount of in a row on the comparative importance of other environmental and non-environmental influences e.g, it is nasty to highlight the acknowledgment of enhancing strategies in the gear of Lyme disease which is caused to humans by ticks from birds recorded in the United Kingdom with greater than ever summer temperatures. Land-use swap better health-care infrastructure and container dull the sound effects of climate swap on creature health, other factors say dominated position over climate change, and it has no no-nonsense function until we give rise to develop our consideration for such medley folks be supposed to be verification of climate variability, highlighted by qualified the health special effects of mortal or spatial climate changes, or steady through the support of climatic factors (e.g. temperature, rainfall, humidity, etc.). Disease caused by a creature that replicates outside being horde shows fluctuations right and proper to the climate conversion (Stanwell-Smith, 1998). A self is not monitored until is exposed to a health danger or suffers illness or other acute health outcomes from that exposure depend on a psychosis regular of openness factors. Vulnerability is the tendency or predilection that gets badly affected by climaterelated health effects. There is a set of vulnerability factors that threaten human health when a person gets exposed to climate variability. Multiple disciplines use terms like exposure, sensitivity, or susceptibility to harm in different ways and different definitions exist in the current literature while the differences between them are ambiguous (IPCC, 2014). All three of these elements can vary temporally and are system-specific (Hayes and Johnson, 2014).

\section{Conclusion}

The belongings of climate variation foliage great impacts on human being health by everincreasing adverse reheat waves, the venture of vector-borne diseases that changes the ecology of vectors like ticks, bedbugs, etc. The dreadful and infectious diseases like Chikungunya, Ebola, (Covid-19) are the outcomes of climate change. Unfortunately, we obtain excluding in sequence on the qualified import of other environmental and non-environmental influences. Land-use change, enhanced healthcare infrastructure can take the edge off the property of climate loose change on individual health. However, other factors cover furthermore dominated position over climate change and it has no feasible expenditure until we carry out discernment for such range individuals must be an attestation of climate variability, highlighted by knowledgeable the health special effects of lay or spatial climate changes or stable through corroborate of climatic factors (e.g. temperature, rainfall, humidity, etc).

In short, health impacts of great measures are probable to be awesomely downbeat and bear a hefty influence on low-income countries anywhere adaptation capability is lowest, but plus on the nearly all vulnerable groups in residential countries. With climate transformation by now underway, vulnerabilities penury to be assessed and costeffective intercession and adaptation options necessity to be identified in the health and other sectors that enclose uninterrupted relations to being healthy. Effective preparation will advantage to take the edge off budding denial health special effects and improvement strategies e.g., via a class of sustainable sources of energy will expand protection by minimizing appearance emissions and extenuating climate changes.

\section{REFERENCES}

Akinbami, L. J., J. E.Moorman, C. Bailey, H. S. Zahran, M. King, C. A. Johnson, and X. Liu, (2012): Trends in Asthma Prevalence, Health Care Use, and Mortality in the United States.

Arneth, A. et al. (2010).Terrestrial biogeochemical feedbacks in the climate system. Nature Geosci. 3, 525-532.

Balbus, J. M. (1998). Human Health. In Handbook on Methods of Climate Change Impact 
Assessment and Adaptation Strategies, Version 2.0, ed.

Bell, J. E., Herring, S. C., Jantarasami, L., Adrianopoli, C., Benedict, K., Conlon, K., \& Quattrochi, D. (2016). Ch. 4: Impacts of Extreme Events on Human Health (pp. 99128). US Global Change Research Program, Washington, DC.)

Bhattacharya S, Sharma C, Dhiman RC, Mitra AP. (2006). Climate change and malaria in India. Curr Sci 90:369-375.

Busby, J. W. (2008). Who cares about the weather?: Climate change and US national security. Security Studies, 17(3), 468-504.

Capstick, S. B., \& Pidgeon, N. F. (2014). What is climate change scepticism? Examination of the concept using a mixed methods study of the UK public. Global Environmental Change, 24: 389-401.

Carslaw, K. S. et al. (2010). A review of natural aerosol interactions and feedbacks within the Earth system. Atmos. Chem. Phys. 10, 17011737

Christophers, S.R., (1960). Aedes aegypti (L.) The Yellow Fever Mosquito. Its Life History, Bionomics and Structure. Cambridge University Press, Cambridge.

Clark, M. P., Gangopadhyay, S., Brandon, D., Werner, K., Hay, L., Rajagopalan, B., \& Yates, D. (2004). A resampling procedure for generating conditioned daily weather sequences. Water Resources Research, 40(4).

Colwell, R.R. (1996). Global climate and infectious disease: the cholera paradigm. Science, 274 (5295), 2025-2031.

Coumou, D., \& Rahmstorf, S. (2012). A decade of weather extremes. Nature climate change, 2(7), 491-496.

CRS Report RL34059, The Carbon Cycle: Implications for Climate Change and Congress, by Peter Folger.

Curtis, F. (2007). Climate change, peak oil, and globalization: contradictions of natural capital. Review of Radical Political Economics 39 (3), 385-390.

Curtis, S., Fair, A., Wistow, J., Val, D. V., \& Oven, K. (2017). Impact of extreme weather events and climate change for health and social care systems. Environmental Health, 16(1), 128.
Delpla, I., Jung, A. V., Baures, E., Clement, M., \& Thomas, O. (2009). Impacts of climate change on surface water quality in relation to drinking water production. Environment international, 35(8), 1225-1233.

Dhiman RC, Pahwa S, Dash AP. (2008). Climate change and Malaria in India: interplay between temperature and mosquitoes. Regional Health Forum, 12:27-31.

Diaz, H. F., and G. McCabe (1999). A possible connection between the 1878 yellow fever epidemic in the southern United States and the 1877-78 El Nino Episode. Bulletin of the American Meteorological Society. 80:21-27.

Epstein PR. (1999). Climate and Health. Science, 285:347-348.

Fantazzini, D., Ho“ok, M., Angelantoni, A. (2011). Global oil risks in the early 21 stcentury. Energy Policy, 39 (12), 7865-7873.

Forster, P. et al. (2007). Climate Change (2007): The Physical Science Basis (eds Solomon, S. et al. Cambridge Univ. Press.

Francis, D., \& Hengeveld, H. (1998). Extreme weather and climate change. Ontario: Environment Canada.

Frank, C., Littman, M., Alpers, K., Hallauer, J., (2006). Vibrio vulnificus wound infections after contact with the Baltic Sea, Germany. Eur. Surg. 11, 1.

Haines, A. \& McMichael, A. J. (1997). Climate change and health: implications for research, monitoring, and policy. British Medical Journal, 315, 870-4.

Haines, A., Kovats, R. S., Campbell-Lendrum, D., \& Corvalán, C. (2006). Climate change and human health: impacts, vulnerability, and mitigation. The Lancet, 367(9528), 21012109.

Hamilton, L. C., \& Keim, B. D. (2009). Regional variation in perceptions about climate change. International Journal of Climatology: A Journal of the Royal Meteorological Society, 29(15), 2348-2352.

Hess, J. J., Eidson, M., Tlumak, J. E., Raab, K. K., \& Luber, G. (2014). An evidence-based public health approach to climate change adaptation. Environmental Health Perspectives, 122(11), 1177-1186.

Howe, K., Clark, M. D., Torroja, C. F., Torrance, J., Berthelot, C., Muffato, M., \& McLaren, S. 
(2013). The zebrafish reference genome sequence and its relationship to the human genome. Nature, 496(7446), 498-503.

Huber, D. G., \& Gulledge, J. (2011). Extreme weather and climate change: Understanding the link, managing the risk. Arlington: Pew Center on Global Climate Change.

IPCC. (2013). Climate change 2013: the physical science basis. In: Stocker TF, Qin D, Plattner G-K, Tignor M, Allen SK, Boschung J, Nauels A, Xia Y, Bex V, Midgley PM (eds) Contribution of working group I to the fifth assessment report of the intergovernmental panel on climate change. Cambridge University Press, Cambridge, United Kingdom and New York, NY. 1535.

IPCC. (2013). Climate Change 2013: The Physical Science Basis. Contribution of Working Group I to the Fifth Assessment Report of the Intergovernmental Panel on Climate Change. Cambridge University Press, Cambridge, UK and New York, NY, 1535

IPCC. (2014). Climate Change 2014: Impacts, Adaptation, and Vulnerability. Part A: Global and Sectoral Aspects. Contribution of Working Group II to the Fifth Assessment Report of the Intergovernmental Panel on Climate Change. 1132 pp., Cambridge University Press, Cambridge, UK and New York, NY.

Johanning, E., Auger, P., Morey, P. R., Yang, C. S., \& Olmsted, E. (2014). Review of health hazards and prevention measures for response and recovery workers and volunteers after natural disasters, flooding, and water damage: mold and dampness. Environmental Health and preventive medicine, 19(2), 93-99.

Johnson, B. J., \& Sukhdeo, M. V. K. (2013). Drought-induced amplification of local and regional West Nile virus infection rates in New Jersey. Journal of medical entomology, 50(1), 195-204.

Johnson, N. B., L. D. Hayes, K. Brown, E. C. Hoo, and K. A. Ethier. (2014). CDC National Health Report: Leading Causes of Morbidity and Mortality and Associated Behavioral Risk and Protective Factors - United States,
(2005-2013). Morbidity and Mortality Weekly Report - Supplements, 63, 3-27.

Jones, K., (2001). Campylobacters in water, sewage and the environment. J. Appl. Microbiol. 90, 68S-79S.

Cochrane, M. A. and C. P. Barber. (2008). Climate Change, Human Land Use and Future Fires in the Amazon. Global Change Biology, 15, (3). 601-612.

Mahowald, N. (2011). Aerosol indirect effects on biogeochemical cycles and climate. Science 334, 794-796.

Marcheggiani, S., Puccinelli, C., Ciadamidaro, S., Della Bella, V., Carere, M., Francesca Blasi, M., \& Mancini, L. (2010). Risks of waterborne disease outbreaks after extreme events. Toxicological \& Environmental Chemistry, 92(3), 593-599.

Matzarakis, A. (2006). Weather-and climate-related information for tourism. Tourism and Hospitality Planning \& Development, 3(2), 99-115.)

McCartney, G., Hanlon, P., Romanes, F. (2008). Climate change and rising energy costs will change everything: a new mindset and action plan for 21 st century public health. Public Health, 122 (7), 658-663.

McGregor, G. R., Ferro, C. A., \& Stephenson, D. B. (2005). Projected changes in extreme weather and climate events in Europe. In Extreme Weather Events and Public Health Responses Springer, Berlin, Heidelberg.

McLaughlin JB, Depoala A, Bopp CA, et al. (2005). Emergence of Vibro parahaemolyticus gastroenteritis associated with consumption of Alaskan oysters and its global implications. New England $\mathrm{J}$ Med, 353 (14),1463-70.

McMichael AJ, Campbell-Lendrum DH, Corvalán CF, Ebi KL, Githeko A, Scheraga JD, et al. (2003). Climate Change and Human HealthRisks and Responses. Geneva:World Health Organization.

McMichael, A. J., Haines, A., Slooff R., \& Kovats, S. (1996). Climate Change and Human Health: an Assessment Prepared by a Task Group on Behalf of the World Health Organization, the World Major Metereological Organization and United 
Nations Environment Program. Geneva: World Health Organization.

Menne B, Murray V. (2013). Floods in the WHO European Region: health effects and their prevention. Copenhagen, Denmark: World Health OrganiationEuropean Office.

Moriarty, P., Honnery, D. (2009). What energy levels can the Earth sustain? Energy Policy 37 (7), 2469-2474.

Mueller, B., \& Seneviratne, S. I. (2012). Hot days induced by precipitation deficits at the global scale. Proceedings of the national academy of sciences, 109(31), 12398-12403.

Obiri-Danso, K., Paul, N., Jones, K. (2001). The effects of UVB and temperature on the survival of natural populations and pure cultures of Campylobacter jejuni, Camp. coli, Camp. lari and urease-positive thermophilic campylobacters (UPTC) in surface waters. $J$. Appl. Microbiol. 90, 256-267.

Patz JA, Gibbs HK, Foley JA, Rogers JV, Smith KR. (2007). Climate change and global health: quantifying a growing ethical crisis. EcoHealth, (4), 397-405.

Patz JA, Olson SH. (2006). Climate change and health: global to local influences on disease risk. Ann Trop Med Parasitol, (100), 535549.

Scott, D., \& Lemieux, C. (2010). Weather and climate information for tourism. Procedia Environmental Sciences, (1), 146-183.

Smith, K.R.; Woodward, A.; Campbell-Lendrum, D. et al. (2014). In Climate Change: Impacts, Adaptation, and Vulnerability. Part A: Global and Sectoral Aspects. Contribution of Working Group II to the Fifth Assessment Report of the Intergovernmental Panel on Climate Change. Field, C.B., Barros, V.R., Dokken, D.J., Mach, K.J., Mastrandewa, M.D., Bilir, T.E., Chatterjee, M., Ebi, K.L., Estrada, Y.O., Genova, R.C., et al. Eds. 2014; Cambridge University Press: Cambridge, UK,; Chapter 11.

Stanke, C., Kerac, M., Prudhomme, C., Medlock, J., \& Murray, V. (2013). Health effects of drought: a systematic review of the evidence. PLoS currents, 5.

Stanwell-Smith, R. (1998). Climate change: implications for European surveillance of infectious diseases. Paper presented at WHO meeting on early human health effects of climate change in Europe. Rome, May.

Stephenson, D. B., Diaz, H. F., \& Murnane, R. J. (2008). Definition, diagnosis, and origin of extreme weather and climate events. Climate Extremes and Society, 340, 11-23.

Stocker TF, Qin D, Plattner G-K,Alexander LV, Allen SK, Bindoff NL, et al. (2013). Technical summary.

T. Tomich, ed. (2003). Forces Driving Tropical Deforestation, ASB (Alternatives to Slashand-Burn) Policy Briefs 06, Nairobi, Kenya, November.

Whitehead, P. G., Wilby, R. L., Battarbee, R. W., Kernan, M., \& Wade, A. J. (2009). A review of the potential impacts of climate change on surface water quality. Hydrological sciences journal, 54(1), 101-123.

Zaval, L., Keenan, E. A., Johnson, E. J., \& Weber, E. U. (2014). How warm days increase belief in global warming. Nature Climate Change, 4(2), 143-147. 